\title{
Faktor-Faktor yang Berhubungan dengan Persiapan Ibu Hamil Trimester III Menjelang Persalinan di Bidan Praktek Mandiri Yuniar Desa Cot Nambak Kecamatan Blang Bintang Kabupaten Aceh Besar
}

\author{
Factors Related to The Preparation of Pregnant Women Trimester III Eve of \\ Labor in The Midwife Practice Self Yuniar Cot Village Nambak Blang Bintang \\ Aceh Besar \\ Nurmala Dewi ${ }^{1}$, Raudhatun Nuzul ZA ${ }^{2}$ \\ ${ }^{1}$ Prodi D-III Kebidanan, Universitas Ubudiyah Indonesia, Banda Aceh, Indonesia \\ ${ }^{2}$ Program Studi D-IV Bidan Pendidik, Universitas Ubudiyah Indonesia, Banda Aceh, Indonesia \\ *Korespondensi Penulis : raudhatun@uui.ac.id
}

\begin{abstract}
Abstrak
Persalinan merupakan hal yang paling ditunggu-tunggu oleh para ibu hamil,sebuah waktu yang menyenangkan namun disisi lain merupakan hal yang paling menebarkan. Untuk mengetahui faktor-faktor apa aja yang berhubungan dengan Persiapan ibu hamil trimester III menghadapi persalinan di Bidan Praktek Mandiri Yuniar Desa Cot Nambak Kecamatan Blang Bintang Kabupaten Aceh Besar tahun 2016. Penelitian ini bersifat Analitik dengan pendekatan Cross cectional. Penelitian ini dilakukan di Bidan praktek mandiri Yuniar Desa Cot Nambak Kecamatan Blang Bintang Kabupaten Aceh Besar.pada tanggal tanggal 24 Juni s/d 17 Juli 2016 pengambilan sampel menggunakan total sampling dengan jumlah sampel 48 orang. Penelitian ini dilakukan pada bulan Juli tahun 2016 Pengumpulan data dilakukan dengan menyebarkan kuesioner. Kemudian di uji statistik mengunakan Chi-quare. Hasil penelitian bahwa dari 48 yang umur $<25$ tahun sebanyak 25 responden diantaranya ibu yang persiapan menghadapi persalinan dengan katagori tidak ada sebanyak 14 responden (56\%), $p$ value 0,033 . Pengetahuan yang berpegetahuan rendah sebanyak 27 responden diantaranya ibu yang persiapan menghadapi persalinan dengan katagori tidak ada sebanyak 16 responden $(59,3 \%), p$ value 0,004 dan Pendapatan tinggi sebanyak 20 responden diantaranya ibu yang persiapan menghadapi persalinan dengan katagori ada sebanyak 20 responden (80\%), $p$ value 0,009. Ada hubungan antara umur, pengetahuan dan pendapatan dengan persiapan ibu hamil trimester III menghadapi persalinan. Diharapkan agar hasil penelitian ini dapat digunakan sebagai tolak ukur dalam menilai tingkat pelayanan kesehatan dan bahan kajian serta informasi bagi tenaga kesehatan sehingga dapat meningkatkan kualitas pelayanan melalui pemberian penyuluhan dan konseling mengenai persiapan persalinan pada saat antenatal care (ANC).
\end{abstract}

Kata Kunci: Persiapan Ibu Hamil Trimester III 


\begin{abstract}
Labor is the most eagerly awaited by the pregnant woman, an exciting time, but on the other hand is the most spread.. To determine the factors associated with any kind Preparation third trimester pregnant women face in the labor Independent Midwife Practice Yuniar village of Cot Nambak District of Blang Bintang, Aceh Besar District in 2016. This study is analytic approach cectional Cross. This research was conducted in independent practice Yuniar Bidan village of Cot Nambak District of Blang Bintang, Aceh Besar district. on June 24, s / d July 17, 2016 using a total sampling sampling with a sample of 48 people. This research was conducted in July 2016. Data was collected by distributing questionnaires. Later in using statistical test Chi-quare. The results that from 48 the age $<25$ years as many as 25 respondents among mothers prepare for childbirth with no category a total of 14 respondents (56\%), p value 0.033. Low berpegetahuan knowledge as much as 27 respondents among mothers prepare for childbirth with no category as many as 16 respondents (59.3\%), p value 0.004 and higher revenues as much as 20 respondents among mothers prepare for childbirth with as many as 20 categories of respondents (80\%), p value 0.009 Conclusions and recommendations: There is a relationship between age, knowledge and income to the preparation of third trimester pregnant women face persalinanSaran: it is expected that the results of this study can be used as a benchmark in assessing the level of health care and study materials as well as information for health workers so as to improve the quality of care through the provision of counseling and counseling about birth preparedness during antenatal care $(A N C)$.
\end{abstract}

Keywords: Preparation Pregnancy Trimester III

\title{
PENDAHULUAN
}

Kehamilan Trimester III sering kali disebut periode menunggu dan waspada karena ibu sudah merasa tidak sabar menunggu kelahiran bayinya dan mulai khawatir dengan diri dan bayinya pada saat melahirkan.Pada saat itu juga merupakan saat persiapan aktif untuk menunggu kelahiran bayi dan menjadi orang tua (Sofie R. 2010).

Kehamilan merupakan hal yang fisiologis.Namun kehamilan yang normal dapat berubah menjadi patologi.Salah satu asuhan yang dilakukan oleh bidan untuk menapis adanya resiko ini yaitu melakukan pendeteksial dini adanya komplikasi atau penyakit yang mungkin terjadi selama hamil muda (Yuni Kusmiati, 2012).

Persiapan persalinan merupakan bagian terpenting dari proses persalinan yang ditujukan untuk meningkatkan kesehatan optimal menjelang persalinan dan segera dapat memberikan laktasi. Persiapan persalinan meliputi persiapan fisik, psikologis dan materi.Persiapan fisik merupakan persiapan yang berhubungan dengan aspek persiapan tubuh untuk mempermudah persalinan dan laktasi, persiapan psikologis adalah persiapan yang berhubungan dengan ketahanan mental terhadap rasa takut dan kecemasan serta aspek 
kognitif tentang persalinan sedangkan persiapan materi merupakan persiapan ibu dan keluarga untuk mendukung kelancaran persalinan dari aspek finansial (Manuaba, 2011).

Persalinan merupakan hal yang paling ditunggu-tunggu oleh para ibu hamil,sebuah waktu yang menyenangkan namun disisi lain merupakan hal yang paling menebarkan. Persalinan terasa akan menyenangkan namun disisi lain merupakan hal yang paling mendebarkan. Persaliana terasa akan menyenangkan karena sikecil yang selama sembilan bulan bersembunyi didalam perut anda akan muncul terlahir kedunia. Disisi lain persalinan menjadi mendebarkan khusus bagi calon ibu baru, dimana terbayang proses persalinan yang menyakitkan, mengeluarkan energi yang begitu banyak dan sebuah perjuangan yang cukup melelahkan.

Munculnya perilaku untuk melakukan persiapan persalinan didukung oleh adanya motivasi untuk melakukan persiapan persalinan, yaitu alasan atau dorongan dalam diri manusia yang menyebabkan seseorang berbuat sesuatu (Sunaryo, 2010).

Menurut WHO (2012) sebagian Angka Kematian Ibu (AKI) yang terjadi dapat dihindari apabila tersedia tenaga pertolongan persalinan yang terampil. Kompetensi adalah prasyarat untuk praktek-praktek terbaik dan memastikan peningkatan kualitas pelayanan kesehatan ibu (Canavan dalam Cham et Ai, 2010).

Memperkirakan lebih dari 585.000 ibu pertahunnya meninggal saat hamil atau persalinan. di Asia Selatan, wanita kemungkinan meninggal 1:18 yang diakibatkan Oleh hamil atau persalinan selama kehidupannya, di banyak Negara Afrika $1: 14$, sedangkan di Amerika Utara hanya $1: 6.366$ lebih dari 50\% kematian terjadi di Negara berkembang sebenarnya dapat di cegah dengan tekhnologi yang ada serta biaya relatif rendah (Sarwono, 2010).

Kematian pada wanita dan bersalin adalah masalah besar di negara berkembang. Di negara berkembang sekitar 25-50\% kematian terjadi pada wanita usia subur. Kematian saat melahirkan biasanya menjadi faktor utama kematian wanita usia muda pada masa puncak produktivitasnya. Angka kematian ibu (AKI) merupakan tolak ukur untuk menilai keadaan pelayanan obstetri disuatu negara.Bila AKI masih tinggi berarti sistem pelayanan obstetri masih buruk, sehingga memerlukan perbaikan (Anbarwati, 2009).

Kematian ibu $90 \%$ terjadi pada saat sekitar persalinan dan $95 \%$ penyebab kematian ibu ada adalah komplikasi obsertri yang sering tidak diperkirakan sebelumnya, maka kebijaksaana depertemen kesehatan untuk mempercepat penurunan AKI adalah memupayakan agar setiap 
persalinan ditolong atau didampingi oleh bidan atau pelayanan obsertri sedekat mungkin diberikan pada ibu hamil. Bidan sebagai tenaga kesehatan juga mempercepat penurunan AKI yaitu dengan salah satu usaha salah satunya adalah pelayanan antenatal care (ANC).Pelayanan antenatal merupakan sarana agar ibu lebih siap menghadapi persalinan (Depkes RI, 2012).

Berdasarkan survey demografi kesehatan indonesia (SDKI) 2007 menunjukkan bahwa angka kematian ibu indonesia masih tinggi yaitu 228/100.000 kelahiran hidup (KH), sedangkan angka kematian bayi (AKB) di indonesia juga masih relatif tinggi yaitu 34/1000 KH (Depkes RI, 2013).

AKI di provinsi aceh mencapai 209/100KH, AKB berada diatas rata nasional yaitu mencapai 40/1000 KH (Dinkes Prov Aceh, 2015).

Berdasarkan data di Bidan Praktek Mandiri Yuniar Desa Cot Nambak Kecamatan Blang Bintang Kabupaten Aceh Besar tercatat dari bulan Januari sampai Desember tahun 2015 Ibu hamil yang berkunjung adalah sebanyak 243 orang dengan ibu hamil Trimster I tercatat 75 orang, trimester II 98 orang, dan trimester III sebanyak 70 orang. Berdasarkan Survey awal yang dilakukan di Bidan praktek mandiri Yuniar Desa Cot nambak Kecamatan Blang Bintang Kabupaten Aceh Besar ibu hamil trismester III yang berkunjung dari bulan januari-April 2016 sebanyak 48 orang. Dari 10 Orang yang dijumpai 6 orang tidak mengetahui tentang Persiapan persalinan, tanda bersalin sampai dengan tanda bahayanya, padahal dalam Proses persalinan diharapkan ibu-ibu hamil harus mengetahui semua tentang Kehamilan, Persiapan persalinan sampai dengan proses persalinan.

Berdasarkan hasil studi pendahuluan awal yang diperoleh tertarik untuk melakukan penelitian tentang "Faktor-faktor yang berhubungan dengan Persiapan ibu hamil trimester III menjelang persalinan di Bidan Praktek Mandiri Yuniar Desa Cot Nambak Kecamatan Kabupaten Aceh Besar Tahun 2016".

\section{METODE PENELITIAN}

Jenis penelitian yang digunakan dalam penelitian ini adalah analitik dengan pendekatan cros sectional untuk mengetahui faktor-faktor yang berhubungan dengan Persiapan ibu hamil trimester III menjelang persalinan di Bidan praktek mandiri Yuniar Desa Cot Nambak Kecamatan Blang Bintang Kabupaten Aceh Besar. Pendekatan croos sectional study yaitu jenis penelitian dimana variabel dependen dan independen dikumpul dalam waktu yang sama pada suatu periode tertentu ( Arikunto, 2006). Penelitian telah dilakukan di Bidan 
praktek mandiri Yuniar Desa Cot Nambak Kecamatan Blang Bintang Kabupaten Aceh Besar. Penelitian ini telah dilaksanakan pada tanggal 24 Juni s/d 17 Juli 2016

\section{HASIL PENELITIAN}

Tabel 1. Distribusi Frekuensi Persiapan Ibu Hamil trimester III Menjelang Persalinan Di Bidan Praktek Mandiri Yuniar Desa Cot Nambak Kecamatan Blang Bintang Kabupaten Aceh Besar Tahun 2016

\begin{tabular}{clccc}
\hline No & & Persiapan Ibu Hamil & f & $\begin{array}{c}\text { Persentase } \\
(\boldsymbol{\%})\end{array}$ \\
\hline 1 & Ada & & 29 & 60,4 \\
2 & Tidak Ada & & 19 & 39,6 \\
\hline & Total & $\mathbf{4 8}$ & $\mathbf{1 0 0}$ \\
\hline
\end{tabular}

Berdasarkan tabel 1 dapat dilihat bahwa dari 48 responden yang ada persiapan ibu hamil trismester III menjelang persalinan yaitu sebanyak 29 responden (60,4\%). Dan 19 responden yang tidak ada persiapan ibu hamil trismester III menjelang persalinan

Tabel 2. Distribusi Frekuensi Umur dengan Ibu Hamil trimester III Menjelang Persalinan di Bidan Praktek Mandiri Yuniar Desa Cot Nambak Kecamatan Blang Bintang Kabupaten Aceh Besar Tahun 2016

\begin{tabular}{ccccc}
\hline No & & Umur & f & $\begin{array}{c}\text { Persentase } \\
(\mathbf{\%})\end{array}$ \\
\hline 1 & $\geq 25$ Tahun & & 23 & 47,9 \\
2 & $<25$ Tahun & & 25 & 52,1 \\
\hline & & Total & $\mathbf{4 8}$ & $\mathbf{1 0 0}$ \\
\hline
\end{tabular}

Berdasarkan tabel 5.2 dapat dilihat bahwa dari 48 responden yang umur $<25$ tahun yaitu sebanyak 25 responden $(52,1 \%)$.

Tabel 3. Distribusi Frekuensi Umur Dengan Ibu Hamil trimester III Menjelang Persalinan Di Bidan Praktek Mandiri Yuniar Desa Cot Nambak Kecamatan Blang Bintang Kabupaten Aceh Besar Tahun 2016

\begin{tabular}{ccccc}
\hline No & & Pengetahuan & f & $\begin{array}{c}\text { Persentase } \\
(\mathbf{\%})\end{array}$ \\
\hline 1 & Tinggi & & 21 & 43,8 \\
2 & Rendah & & 27 & 56,2 \\
\hline & & Total & $\mathbf{4 8}$ & $\mathbf{1 0 0}$ \\
\hline
\end{tabular}


Berdasarkan tabel 3 dapat dilihat bahwa dari 48 responden yang berpengetahuan rendah tentang persiapan menghadapi persalinan yaitu sebanyak 27 responden $(56,2 \%)$.

Tabel 4. Distribusi Frekuensi Pendapatan dengan Ibu Hamil Trimester III Menjelang Persalinan di Bidan Praktek Mandiri Yuniar Desa Cot Nambak Kecamatan Blang Bintang Kabupaten Aceh Besar Tahun 2016

\begin{tabular}{cccc}
\hline No & Pendapatan & f & $\begin{array}{c}\text { Persentase } \\
(\boldsymbol{\%})\end{array}$ \\
\hline 1 & Tinggi & 25 & 52,1 \\
2 & Rendah & 23 & 47,9 \\
\hline & Total & $\mathbf{4 8}$ & $\mathbf{1 0 0}$ \\
\hline
\end{tabular}

Berdasarkan tabel 4 dapat dilihat bahwa dari 48 responden yang berpendapatan tinggi yaitu sebanyak 25 responden $(52,1 \%)$.

Tabel 5. Hubungan Umur Dengan Persiapan Ibu Hamil Trimester III Menghadapi Persalinan Di Bidan Praktek Mandiri Yuniar Desa Cot Nambak Kecamatan Blang Bintang Kabupaten Aceh Besar Tahun 2016

\begin{tabular}{|c|c|c|c|c|c|c|c|c|}
\hline \multirow{3}{*}{ No } & \multirow{3}{*}{ Umur } & \multicolumn{4}{|c|}{$\begin{array}{c}\text { Persiapan Menghadapi } \\
\text { Persalinan }\end{array}$} & \multirow{2}{*}{\multicolumn{2}{|c|}{ Total }} & \multirow{3}{*}{ P-Value } \\
\hline & & \multicolumn{2}{|c|}{ Ada } & \multicolumn{2}{|c|}{ Tidak Ada } & & & \\
\hline & & $\mathbf{f}$ & $\%$ & $\mathbf{F}$ & $\%$ & $\mathbf{f}$ & $\%$ & \\
\hline 1. & $\geq 25$ Tahun & 18 & 78,3 & 5 & 21,7 & 23 & 100 & \\
\hline 2. & $<25$ Tahun & 11 & 44 & 14 & 56 & 25 & 100 & 0,033 \\
\hline
\end{tabular}

Berdasarkan tabel 5 Hasil Statistik hubungan umur dengan Persiapan menghadapi persalinan Trimester III diperoleh bahwa ada sebanyak 18 responden (78,3\%) ibu yang umurnya $\geq 25$ tahun dengan kategori ada persiapan persalinannya, sedangkan ibu yang umurnya $<25$ tahun ada sebanyak 14responden (56\%) dengan kategori tidak ada persiapan persalinannya.

Hasil analisis statistik menggunakan uji chi-square didapatkan p value 0,033. Sehingga dapat disimpulkan bahwa $\mathrm{p}<0,05$ yang artinya Ha diterima atau terdapat hubungan umur dengan persiapan ibu hamil trimester III menghadapi persalinan Di Bidan Praktek Mandiri Yuniar Desa Cot Nambak Kecamatan Blang Bintang Kabupaten Aceh Besar Tahun 2016. 
Tabel 6. Hubungan Pengetahuan Dengan Persiapan Ibu Hamil Trimester III Menghadapi Persalinan Di Bidan Praktek Mandiri Yuniar Desa Cot Nambak Kecamatan Blang Bintang Kabupaten Aceh Besar Tahun 2016

\begin{tabular}{|c|c|c|c|c|c|c|c|c|}
\hline \multirow{3}{*}{ No } & \multirow{3}{*}{ Pengetahuan } & \multicolumn{4}{|c|}{$\begin{array}{l}\text { Persiapan Menghadapi } \\
\text { Persalinan } \\
\end{array}$} & \multirow{2}{*}{\multicolumn{2}{|c|}{ Total }} & \multirow{3}{*}{ P-Value } \\
\hline & & \multicolumn{2}{|c|}{ Ada } & \multicolumn{2}{|c|}{ Tidak Ada } & & & \\
\hline & & $\mathbf{f}$ & $\%$ & $\mathbf{F}$ & $\%$ & $\mathbf{f}$ & $\%$ & \\
\hline 1. & Tinggi & 18 & 85,7 & 3 & 14,3 & 21 & 100 & \\
\hline 2. & Rendah & 11 & 40,7 & 16 & 59,3 & 27 & 100 & 0,004 \\
\hline
\end{tabular}

Berdasarkan tabel 6 hasil statistik hubungan pengetahuan dengan persiapan menghadapi persalinan Trimester III diperoleh bahwa ada sebanyak 18 responden $(85,7 \%)$ yang mempunyai pengetahuan tinggi dengan kategori ada persiapan persalinannya, sedangkan ibu yang pengetahuannya rendah sebanyak 16 responden $(59,3 \%)$ dengan kategori tidak ada persiapan persalinannya.

Hasil analisis statistik menggunakan uji chi-square didapatkan p value 0,004. Sehingga dapat disimpulkan bahwa $\mathrm{p}<0,05$ yang artinya Ha diterima atau terdapat hubungan pengetahuan dengan persiapan ibu hamil trimester III menghadapi persalinan Di Bidan Praktek Mandiri Yuniar Desa Cot Nambak Kecamatan Blang Bintang Kabupaten Aceh Besar Tahun 2016.

Tabel 7. Hubungan Pendapatan Dengan Persiapan Ibu Hamil Trimester III Menghadapi Persalinan Di Bidan Praktek Mandiri Yunia Desa Cot Nambak Kecamatan Blang Bintang Kabupaten Aceh Besar Tahun 2016

\begin{tabular}{|c|c|c|c|c|c|c|c|c|}
\hline \multirow{3}{*}{ No } & \multirow{3}{*}{ Pendapatan } & \multicolumn{4}{|c|}{$\begin{array}{c}\text { Persiapan Menghadapi } \\
\text { Persalinan }\end{array}$} & \multirow{2}{*}{\multicolumn{2}{|c|}{ Total }} & \multirow{3}{*}{ P-Value } \\
\hline & & \multicolumn{2}{|c|}{ Ada } & \multicolumn{2}{|c|}{ Tidak Ada } & & & \\
\hline & & $\mathbf{f}$ & $\%$ & $\mathbf{F}$ & $\%$ & $\mathbf{f}$ & $\%$ & \\
\hline 1. & Tinggi & 20 & 80 & 5 & 20 & 25 & 100 & \\
\hline 2. & Rendah & 9 & 39,1 & 14 & 60,9 & 23 & 100 & 0,009 \\
\hline
\end{tabular}

Berdasarkan tabel 7 hasil statistik hubungan pendapatan dengan persiapan menghadapi persalinan Trimester III diperoleh bahwa ada sebanyak 20 responden (80\%) yang mempunyai pendapatan tinggi dengan kategori ada persiapan persalinannya, Sedangkan ibu yang pendapatannya rendah ada sebanyak 14 responden(60,9\%) dengan kategori tidak ada persiapan persalinannya. 
Hasil analisis statistik menggunakan uji chi-square didapatkan p value 0,009. Sehingga dapat disimpulkan bahwa $\mathrm{p}<0,05$ yang artinya Ha diterima atau terdapat hubungan pendapatan dengan persiapan ibu hamil trimester III menghadapi persalinan Di Bidan Praktek Mandiri Yuniar Desa Cot Nambak Kecamatan Blang Bintang Kabupaten Aceh Besar Tahun 2016.

\section{Pembahasan}

1. Hubungan Umur Dengan Persiapan Ibu Hamil Trimester III Menghadapi Persalinan

Berdasarkan hasil penelitian yang telah dilakukan oleh peneliti menunjukkan bahawa dari hasil analisis statistik menggunakan uji chi-square didapatkan $p$ value 0,033. Sehingga dapat disimpulkan bahwa $\mathrm{p}<0,05$ yang artinya Ha diterima atau terdapat hubungan umur dengan persiapan ibu hamil trimester III menghadapi persalinan Di Bidan Praktek Mandiri Yuniar Desa Cot Nambak Kecamatan Blang Bintang Kabupaten Aceh Besar Tahun 2016.

Hasil penelitian ini sejalan dengan penelitan yang telah dilakukan Khairunnisak (2012), yang berjudul faktor-faktor yang mempengaruhi persiapan persalinan pada ibu hamil di wilayah kerja puskesmas Lageun Kecamatan Sampoiniet Kabupaten Aceh Jaya menunjukkan bahwa ada pengaruh umur terhadap persiapan persalinan pada ibu hamil ( $\mathrm{p}$ value 0,021$)$.

Hasil penelitian Lisa, (2014), yang berjudul "Faktor-Faktor Mempengaruhi Pada hamil trimester III terhadap persiapan persalinan diPuskesmas Bineh Krueng Kecamatan Tangan-Tangan Kabupaten Aceh Barat Daya" dari 13 responden yang berada pada katagori umur muda negatif dalam persiapan persalinan sebanyak 84,6\%, dan dari 10 responden yang berada pada katagori umur tua negatif dalam persiapan persalinan sebanyak $70 \%$.Hasil analisa statistik menggunakan uji chi-square diperoleh p value 0,002 yang artinya Ha diterima atau terdapat pengaruh umur ibu hamil trimester III terhadap persiapan persalinan di Puskesmas Bineh Krueng Kecamatan Tangan-Tangan Kabupaten Aceh Barat Daya.

Menurut Marani (2011) umur adalah usia ibu yang secara garis besar menjadi Indikator dalam kedewasaan dalm setiap pengambilan keputusan yang mengacu pada setiap pengalaman.Usia yang cukup dalam mengawali atau memasuki masa perkawinan dan kehamilan akan membantu seseorang dalam kematangan dalam menghadapi 
persoalan atau masalah, dalam hal ini menghadapi kehamilan dan perubahan selama hamil.

Menurut teori Salmah, (2006).untuk umur yang dianggap paling aman menjalani kehamilan dan persalinan adalah 20-35 tahun. Di rentang usia ini kondisi fisik wanita dalam keadaan prima, rahim sudah mampu memberi perlindungan, mental pun siap untuk merawat dan menjaga kehamilannya secara hati-hati. Kehamilan di umur kurang dari 20 tahun bisa menimbulkan masalah, karena kondisi fisik belum 100\% siap.Beberapa resiko yang bisa terjadi pada kehamilan diumur ini adalah kecenderungan naiknya tekanan darah dan pertumbuhan janin terhambat.Di luar urusan kehamilan dan persalinan, resiko kanker leher rahim meningkat akibat hubungan seks dan melahirkan.Sedangkan setelah umur 35 tahun, sebagian wanita digolongkan pada kehamilan beresiko tinggi terhadap kelainan bawaan dan adanya penyulit pada waktu persalinan. Di kurun umur ini, angka kematian ibu dan bayi meningkat.

Menurut peneliti bahwa ada berhubungan dengan peresiapan ibu hamil dalam persalinan. Karena pada umur yang masih muda, selain sistem reproduksi yang belum matang keadaan psikologi ibu juga belum sepenuhnya memiliki naluri untuk menjalani persalinan dan menjadi seorang ibu. Begitu juga pada umur yang terlalu tua, walaupun sudah memiliki kesiapan psikologi yang matang namun sistem reproduksi ibu justru akan rentan terhadap kehamilan.

2. Hubungan Pengetahuan Dengan Persiapan Ibu Hamil Trimester III Menghadapi Persalinan

Berdasarkan hasil penelitian yang telah dilakukan oleh peneliti menunjukkan dari hasil analisis statistik menggunakan uji chi-squaredidapatkan p value 0,004. Sehingga dapat disimpulkan bahwa $\mathrm{p}<0,05$ yang artinya Ha diterima atau terdapat hubungan pengetahuan dengan persiapan ibu hamil trimester III menghadapi persalinan Di Bidan Praktek Mandiri Yuniar Desa Cot Nambak Kecamatan Blang Bintang Kabupaten Aceh Besar Tahun 2016.

Berdasarkan hasil penelitian Khairunnisak (2012), yang berjudul faktor-faktor yang mempengaruhi persiapan persalinan pada ibu hamil di wilayah kerja puskesmas Lageun Kecamatan Sampoiniet Kabupaten Aceh Jaya menunjukkan bahwa ada pengetahuan terhadap persiapan persalinan pada ibu hamil ( $\mathrm{p}$ value 0,017 ) 
Hasil penelitian yang dilakukan oleh Silviana (2011), yang berjudul faktor-faktor yang mempengaruhi ibu hamil trismester III terhadap persiapan persalinan, di UPT puskesmas Gajahan Surakarta menunjukkan bahwa ada pengaruh antara pengetahuan ibu hamil trimester III terhadap persiapan persalinan.

Pengetahuan adalah kesan didalam pikiran manusia sebagai hasil penggunaan pancainderanya.Pengetahuan sangat berbeda dengan kepercayaan (beliefs), takhayul (superstition) dan penerangan-penerangan yang keliru (misinformation). Pengetahuan adalah segala apa yang diketahui berdasarkan pengalaman yang didapatkan oleh setiap manusia (Mubarak, 2011).

Pengetahuan merupakan hasil dari tahu dan ini terjadi setelah orang melakukan penginderaan terhadap suatu objek tertentu.Penginderaan itu terjadi melalui panca indera manusia, yakni penciuman, rasa dan raba. Sebagian penginderaaan diperoleh melaui mata dan telinga (Notoatmodjo, 2010).

Menurut asumsi peneliti bahwa, tingkat pengetahuan yang dimiliki oleh seorang ibu hamil akan sangat menentukan kesiapan ibu hamil trimester III dalam menyiapkan persalinannya. Semakin baik pengetahuan yang dimiliki oleh ibu hamil trimester III maka akan semakin siap pula ibu hamil tersebut dalam persiapan persalinan, begitu juga sebaliknya, semakin kurang pengetahuan yang dimiliki oleh ibu hamil, maka akan semakin tidak siap pula ibu hamil tersebut dalam persiapan persalinan, hal ini di karenakan ibu hamil yang memiliki tingkat pengetahuan yang baik lebih tahu hal-hal apa saja yang harus dipersiapkan untuk proses persalinan serta kebutuhan untuk menyambut kelahiran sang bayi.

3. Hubungan Pendapatan Dengan Persiapan Ibu Hamil Trimester III Menghadapi Persalinan Berdasarkan hasil penelitian yang telah dilakukan oleh peneliti menunjukkan dari hasil analisis statistik menggunakan uji chi-square didapatkan $p$ value 0,009. Sehingga dapat disimpulkan bahwa $\mathrm{p}<0,05$ yang artinya Ha diterima atau terdapat hubungan pendapatan dengan persiapan ibu hamil trimester III menghadapi persalinan Di Bidan Praktek Mandiri Yuniar Desa Cot Nambak Kecamatan Blang Bintang Kabupaten Aceh Besar Tahun 2016.

Berdasarkan hasil penelitian Nurhayati (2011) yang berjudul hubungan dukungan keluarga, pendapatan, dan informasi dengan kesiapan mengahadapi persalinan di wilayah 
kerja puskesmas pasi raya kecamatan Teunom tahun 2011 menyatakan bahwa ada hubungan pendapatan dengan kesiapan menghadapi persalinan ( $p$ value 0,008 )

Pendapatan adalah semua penghasilan yang didapat oleh keluarga abaik berupa uang ataupun jasa.Untuk masyarakat yang mempunyai penghasilan yang kecil, mereka berupaya hasil dari pekerjaannya hanya untuk memenuhi kebutuhan sehari-hari.Untuk keluarga yang berpenghasilan menengah mereka lebih terearah kepada pemenuhan kebutuhan pokok yang layak seperti makan, pakaian, perumahan, pendidikan dan lai-lain. Sedangkan keluarga yang berpenghasilan tinggi dan berkecukupan mereka akan memenuhi segala keinginan yang mereka inginkan termasuk keinginan untuk menyekolahkan anak mereka ke jenjang pendidikan yang lebih tinggi (Azwar, 2006).

Persiapan persalinan yang perlu diperhitungan juga adalah masalah transportasi, misalmya jarak tempuh dari rumah ketujuan membutuhkan waktu berapa lama, jenis alat transportasi, sulit atau mudahkan lokasi yang ditempuh, karena hal ini akan mempengaruhi keterlambatan pertolongan. Untuk mengurangi tingkat kecemasan dari social ekonomi disarankan kelaurga sudah mengikuti kelas menjadi orang tua mulai dari trimester I, II dan III. Agar proses persalinan berjalan secara normal, ibu selamat dan bayinya sehat perlu pendukung lain yaitu dana. Pendanaan yang memadai perlu direncanakan jauh sebelum masa persalinan tiba dengan cara menabung, dapat melalui arisan, tabungan ibu bersalin atau menabung di bank (Salmah, 2006).

Menurut peneliti bahwa, dengan penghasilan yang cukup, ibu hamil memiliki peluang yang besar untuk mendapatkan fasilitas yang lebih baik dalam persalinan serta mempersiapkan segala yang dibutuhkan untuk proses persalinan dan menyambut kelahiran sang bayi dengan lebih maksimal. Berbeda dengan ibu yang memiliki pendapatan rendah, ibu dengan pendapatan rendah walaupun sudah tahu apa-apa saja yang harus dipersiapkan untuk proses persalinan, namun karena keterbatasan ekonomi, maka persiapan yang dilakukanpun akan semakin minim. Oleh karena itu pendapatan yang cukup sangat diharapkan bagi setiap keluarga, selain untuk memenuhi kebutuhan seharihari juga untuk persiapan - persiapan yang diperlukan di masa yang akan mendatang khususnya untuk persalinan karena pendapatan seseorang sangat mempengaruhi persiapan persalinan dalam sebuah keluarga. 


\section{KESIMPULAN}

Berdasarkan hasil penelitian dari faktor-faktor apa aja yang berhubungan dengan Persiapan ibu hamil trimester III menghadapi persalinan di Bidan Praktek Mandiri Yuniar Desa Cot Nambak Kecamatan Blang Bintang Kabupaten Aceh Besar tahun 2016. Maka dapat disimpulkan sebagai berikut :

1. Terdapat hubungan umur dengan persiapan ibu hamil trimester III menghadapi persalinan Di Bidan Praktek Mandiri Yuniar Desa Cot Nambak Kecamatan Blang Bintang Kabupaten Aceh Besar Tahun 2016, $p$ value 0,033 yang artinya Ha diterima.

2. Terdapat hubungan pengetahuan dengan persiapan ibu hamil trimester III menghadapi persalinan Di Bidan Praktek Mandiri Yuniar Desa Cot Nambak Kecamatan Blang Bintang Kabupaten Aceh Besar Tahun 2016, $p$ value 0,004 yang artinya Ha diterima.

3. Terdapat hubungan pendapatan dengan persiapan ibu hamil trimester III menghadapi persalinan Di Bidan Praktek Mandiri Yuniar Desa Cot Nambak Kecamatan Blang Bintang Kabupaten Aceh Besar Tahun 2016, $p$ value 0,009 yang artinya Ha diterima.

\section{SARAN}

Diharapkan agar hasil penelitian ini dapat digunakan sebagai tolak ukur dalam menilai tingkat pelayanan kesehatan dan bahan kajian serta informasi bagi tenaga kesehatan sehingga dapat meningkatkan kualitas pelayanan melalui pemberian penyuluhan dan konseling mengenai persiapan persalinan pada saat antenatal care (ANC). Diharapkan bagi masyarakat dapat menambah pengalaman dalam bidang penelitian dan mengetahui tentang persiapan ibu hamil trimester III menghadapi persalinan.

\section{DAFTAR PUSTAKA}

Anonim.(2010). Profil Kesehatan Indonesia.Jakarta : Kementerian Kesehatan RI

Ambarwati, Wulandari. (2009). Asuhan Kebidanan Nifas. Edisi 5. Yokyakarta: Nuha Medika Khairunnisak (2012), Faktor-Faktor Yang Mempengaruhi Persiapan Persalinan Pada Ibu Hamil Di Wilayah Kerja Puskesmas Lageun Kecamatan Sampoiniet Kabupaten Aceh Jaya

Kusmiati, dkk (2009).Perawatan Ibu Hamil (Asuhan Ibu Hamil), Yogyakarta: Fitramaya

Lisa, (2014), Faktor-Faktor Mempengaruhi Pada hamil trimester III terhadap persiapan persalinan diPuskesmas Bineh Krueng Kecamatan Tangan-Tangan Kabupaten Aceh Barat Daya 
Manuaba, (2011) .GawatDarurat Obstetri Ginekologi dan Obstetri Ginekologi Sosial Untuk Profesi Bidan.Jakarta : ECG

Muareen Bard, (2011) Persiapan kehamilan dan kelahiran bayi anda. PT. Bina Pustaka

Mariani, (2011). Faktor-Faktor Yang Berhubungan Dengan Kesiapan Ibu Hamil Persalinan

Nurhayati (2011). hubungan dukungan keluarga, pendapatan, dan informasi dengan kesiapan mengahadapi persalinan di wilayah kerja puskesmas pasi raya kecamatan Teunom tahun 2011

Pemda Aceh, (2015). Upah Minimimum Provinsi Aceh (UMP)

Rohani, dan Saswita Reni (2011), Asuhan Kebidanan Pada Masa Persalinan, Salemba Medika, Jakarta

Saifudin,A.B, (2011). Buku Acuan Nasional Pelayanan Kesehatan Maternal dan Neontal. Jakarta: JNPKKR-POGI bekerjasama dengan Yayasan Bina Pustaka Sarwono Prawirohardjo.

Sunaryo, (2010).Buku Acuan Pelayanan Kesehatan Maternal dan Neonatal.Jakarta : Yayasan Bina Pustaka.

Sarwono, Solita. (2010). Sosiologi Kesehatan, Yogyakarta : Gadjah Mada University Press

Suhardjo (2007). Asuhan Kebidanan Pada Masa Nifas. Jakarta : Salemba Medika.

Sunarsih, (2012)..Masa kehamilan dan persalinan, Jakarta : Elex media komputindo

Sumarah, dkk (2009).Perawatan Ibu Bersalin (Asuhan Kebidanan Pada Ibu Bersalin. Yogyakarta :Fitrimaya

Sulistyawati, A,. (2011). Asuhan Kebidanan Pada Ibu Bersalin. Jakarta : Salemba Medika 